\title{
Ion Exchange and Protonation Equilibria of an Amphoteric Ion-exchange Resin in the Presence of Simple Salt
}

\author{
Yoshinobu Mirazaki, ${ }^{\dagger}$ Hui Qu, and Junko KonaKa \\ Department of Chemistry, Fukuoka University of Education, Akamabunkyo-machi, \\ Munakata, Fukuoka 811-4192, Japan
}

\begin{abstract}
The influence of simple salts on the ion exchange and protonation equilibria of an amphoteric ion-exchange resin, which has strong base and weak acid moieties in a single functional group fixed onto the styrene-DVB matrix, has been investigated. Concentrations of ionic species in the amphoteric ion-exchange resin in equilibrium with various sodium salt solutions were estimated by ${ }^{23} \mathrm{Na} \mathrm{NMR}$ spectroscopy. For the $\mathrm{NaClO}_{4}$ system, the ratio of sodium ion concentration in the resin phase to that in the equilibrium solution was greater than 1 and increased with a decrease in the salt concentration. In contrast to an ordinary cation-exchange resin, the ion exchange behavior of $\mathrm{Mg}^{2+}$ and $\mathrm{Ca}^{2+}$ on the amphoteric ion-exchange resin showed a marked dependence on the kinds of salts: the distribution coefficients for the $\mathrm{NaCl}$ system were independent of the salt concentration, while the $\log D v s . \log \left[\mathrm{Na}^{+}\right]$plots for the $\mathrm{NaClO}_{4}$ system showed linear relationships with slopes being neither -2 nor 0 . Apparent protonation constants of the carboxylate in the functional group of the resin in equilibrium with $\mathrm{NaClO}_{4}$ solutions were greater than those with $\mathrm{NaCl}$ solutions. The ion exchange and protonation properties of the amphoteric ion-exchange resin were elucidated on the basis of the information about the salt concentrations in the resin phase estimated by the NMR method.
\end{abstract}

(Received May 12, 2008; Accepted June 9, 2008; Published September 10, 2008)

\section{Introduction}

Amphoteric ion-exchange resins are promising stationary phases for liquid chromatography. ${ }^{1} \quad$ Because the resin contains positively and negatively charged groups immobilized on a single resin particle, it simultaneously retains anions and cations from an external solution. The separation of anions and cations can be achieved by a single column operation, and the use of water as an eluent is possible for some separations. This can drastically improve the sensitivity of detection, especially when conductivity detection is used.

Retardion resin 11A-8, one of the well-known amphoteric ionexchange resins, is a strong base anion-exchange resin trapping polyacrylate (a so-called snake-cage resin). The resin has become commercially available since 1957 and has been used for the separation of electrolytes and non-electrolytes. ${ }^{2-4}$ It has, however, some unfavorable features; i.e., there is a difference in the number of positively and negatively charged groups (the quaternary ammonium and carboxylic groups) fixed onto the resin particle, and the trapped polyacrylate leaches out from the cage. ${ }^{5}$ The amphoteric ion-exchange resins we have examined in this work have strong base and weak acid moieties in the single functional group (Fig. 1) fixed onto the styrene-DVB matrix. Therefore, they have the same number of fixed positive and negative charges, and show high stability as well as less shrinking and swelling properties. Although these resins will offer new interesting separation possibilities, very few studies can be found. ${ }^{5}$

† To whom correspondence should be addressed.

E-mail: miyazaky@fukuoka-edu.ac.jp
The ion exchange selectivity is characterized by the thermodynamic equilibrium constant; ${ }^{6-8}$ however, a direct thermodynamic study of the interactions in the ion-exchange resin itself is seldom possible. We have already shown that NMR spectroscopy provides unique methods for probing the adsorbed species and for elucidating the solution environment inside the resin phase. ${ }^{9-13}$ In the present study, the concentrations of ionic species in the amphoteric ion-exchange resin in equilibrium with various sodium salt solutions were estimated by ${ }^{23} \mathrm{Na}$ NMR spectroscopy. On the basis of this information, we elucidated the ion exchange and protonation properties of the amphoteric ion-exchange resin in the $\mathrm{NaCl}$ and $\mathrm{NaClO}_{4}$ solutions.

\section{Experimental}

Resins and reagents

The amphoteric ion-exchange resins, DIAION AMP01 and DSR01 (Mitsubishi Chemical Co.), were used in this work.

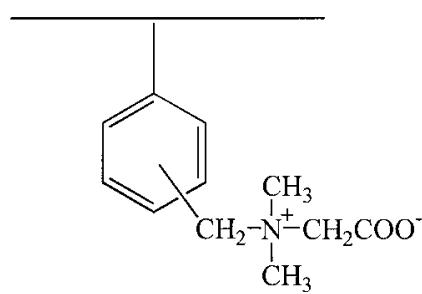

Fig. 1 The functional group of the examined amphoteric ionexchange resin. 
The resins were placed into a glass column, a $1 \mathrm{~mol} \mathrm{dm}^{-3} \mathrm{HCl}$ solution was passed through them, and then they were washed thoroughly with water. The prepared resins were stored under an air-dried condition. The amounts of the functional group were estimated by subtracting the amounts of acid $(\mathrm{HCl}$ or $\mathrm{HClO}_{4}$ ) remaining in the acid solutions equilibrated with the resins from the initial amounts at a sufficiently high acid concentration. The water content of the resin and the interstitial volume of the resin bed were obtained by a column operation, ${ }^{14}$ and the volume ratio of the resin internal solution to the external solution for the bed, $R_{v}$, was then estimated. Strong and weak acid cation-exchange resins, Bio-Rad AG 50W-X4 and Bio-Rex 70 (Bio-Rad Laboratories, Inc.), of the sodium ion form were used for comparison. Other reagents were of analytical grade and were used as received. All solutions were prepared with deionized water.

\section{Distribution measurements}

The ion exchange behaviors of $\mathrm{Mg}^{2+}$ and $\mathrm{Ca}^{2+}$ on the amphoteric ion-exchange resins were examined by a batch technique. A $20-$ $\mathrm{cm}^{3}$ volume of sodium chloride or sodium perchlorate solution of a desired concentration containing a small amount of $\mathrm{Mg}^{2+}$ or $\mathrm{Ca}^{2+}$ was equilibrated with $0.3 \mathrm{~g}$ of the air-dried resin. After the equilibration had been reached, the concentration of the divalent cation in the equilibrium solution was spectrophotometrically determined using Eriochrome Black $T$ (2-hydroxy-1-(1hydroxy-2-naphthylazo)-6-nitro-4-naphthalenesulfonic acid, sodium salt) for $\mathrm{Mg}$ and Murexide (Purpuric acid, ammonium salt) for Ca. The distribution coefficient, $D$, was calculated from the analytical data according to the equation: $D\left(\mathrm{~cm}^{3} / \mathrm{g}\right)=$ $V\left(C_{\text {int }}-C_{\text {eq }}\right) /\left(m C_{\text {eq }}\right)$, where $V$ is the volume of the solution (20 $\left.\mathrm{cm}^{3}\right), C_{\text {int }}$ and $C_{\text {eq }}$ are the concentrations of the divalent cation in the original and the equilibrium solutions $\left(\mathrm{mol} \mathrm{dm}^{-3}\right)$, and $m$ is the mass of the air-dried resin $(\mathrm{g})$.

\section{NMR measurements for the resin}

The ${ }^{23} \mathrm{Na}$ NMR spectra were recorded by a JEOL JNMECX400P spectrometer at the resonance frequency of 105.7 MHz. The NMR parameters were as follows: a flip angle of $c a$. $90^{\circ}(9.8 \mu \mathrm{s})$, a pulse repetition time of $1 \mathrm{~s}$ and a spectral width of $13.2 \mathrm{kHz}$. The field frequency lock was achieved with a deuterium resonance of $\mathrm{D}_{2} \mathrm{O}$ in a concentric capillary tube. A series of sodium salt solutions of different concentrations were equilibrated with $0.3 \mathrm{~g}$ of the amphoteric ion-exchange resins. After equilibration, the resins were loaded into NMR sample tubes together with small amounts of the equilibrium solutions, and then the NMR spectra for the resin beds were measured in the same way as that for an ordinary solution sample.9-13 Overlapping signals were resolved into individual peaks by a Lorentzian curve-fitting method. ${ }^{15}$

\section{Titrations of the resin}

Potentiometric titrations were performed with an automatic titrator AT-510 (Kyoto Electronics) under an atmosphere of nitrogen gas at $298 \mathrm{~K}$. Concentrations of free protons, $\left[\mathrm{H}^{+}\right]$, were obtained from the electromotive force (emf) of a glass electrode C-172 (Kyoto Electronics) according to the Nernsttype equation, $E=E_{0}+59.15 f \log \left[\mathrm{H}^{+}\right]-E_{\mathrm{J}}\left[\mathrm{H}^{+}\right]$, where $f, E_{0}$ and $E_{\mathrm{J}}$ are constants whose values were determined in advance by a Gran-plot at each sample titration. ${ }^{16}$ The sample titrations were done on the amphoteric ion-exchange resins in equilibrium with $\mathrm{NaCl}$ or $\mathrm{NaClO}_{4}$ solutions at various ionic strengths.

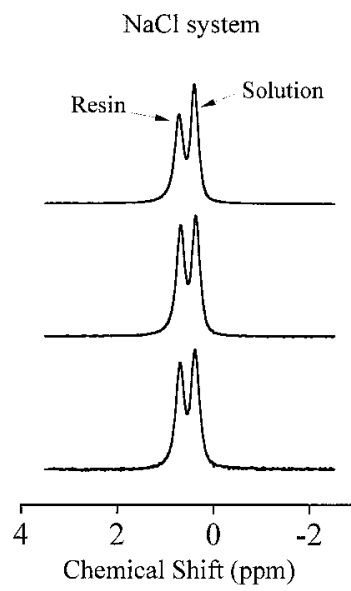

(c)

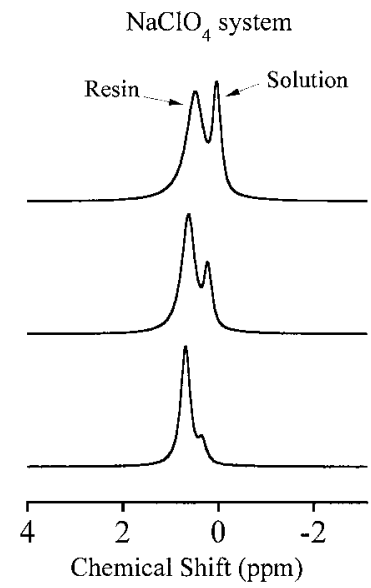

Fig. 2 The ${ }^{23} \mathrm{Na}$ NMR spectra for the amphoteric ion-exchange resin beds in equilibrium with $\mathrm{NaCl}$ or $\mathrm{NaClO}_{4}$ solutions at different concentrations. Resin, $0.3 \mathrm{~g}$ AMP01; solution, $20 \mathrm{~cm}^{3} \mathrm{NaCl}$ or $\mathrm{NaClO}_{4}$ solutions (a) 0.03 , (b) 0.2 , (c) $0.5 \mathrm{~mol} \mathrm{dm}^{-3}$.

\section{Results and Discussion}

Electrolyte concentrations in the amphoteric ion-exchange resins The amounts of the functional group were estimated to be 3.12 $\mathrm{mmol} / \mathrm{g}$ for both AMP01 and DSR01. In order to understand the influence of simple salts on the ion exchange and protonation equilibria of the amphoteric ion-exchange resins, we estimated the concentrations of the simple ions in the resin phases by the NMR method. The amphoteric ion-exchange resins, which had been equilibrated with various sodium salt solutions at different concentrations, were loaded into NMR sample tubes together with small amounts of the equilibrium solutions, and the ${ }^{23} \mathrm{Na}$ NMR spectra for the resin beds were then recorded (Fig. 2). Two signals were observed: the lower field signal was assigned to the sodium ion in the resin phase and the other to that in the equilibrium solution. It is obvious that the exchange rate of the sodium ion between the resin phase and the external solution was sufficiently slow on the NMR time-scale. The signal intensity ratios of the resin to the solution, $\bar{A}_{\mathrm{Na}} / A_{\mathrm{Na}}$, were evaluated from the NMR data and were then plotted versus the salt concentrations (Fig. 3). The signal intensity ratios were nearly constant for the $\mathrm{NaCl}$ system over a wide concentration range. For the $\mathrm{NaClO}_{4}$ system, however, the $\bar{A}_{\mathrm{Na}} / A_{\mathrm{Na}}$ values were strongly dependent on the concentrations and became greater at the low concentrations. The ratio, $\bar{A}_{\mathrm{Na}} / A_{\mathrm{Na}}$, can be written as:

$$
\bar{A}_{\mathrm{Na}} / A_{\mathrm{Na}}=R_{\mathrm{V}}\left[\overline{\mathrm{Na}^{+}}\right] /\left[\mathrm{Na}^{+}\right]
$$

where the upper bar refers to the resin phase, and $R_{\mathrm{v}}$ is the volume ratio of the resin internal solution (resin phase) to the external solution in an NMR sample tube. Because the $R_{\mathrm{v}}$ values could be almost constant irrespective of the salt concentrations under the experimental conditions, the signal intensity ratio should be nearly proportional to the ratio of the $\mathrm{Na}^{+}$concentration in the resin phase to that in the equilibrium solution. Moreover, the constant ratio for the $\mathrm{NaCl}$ system over the wide concentration range should be attained as a result of the same $\mathrm{Na}^{+}$concentrations between the resin phase and the

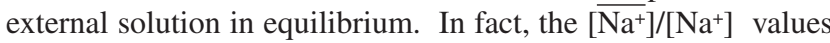
could roughly be estimated to be nearly $1(0.97-1.16)$ from Eq. (1) with $R_{\mathrm{V}}=0.83$ obtained by the column operation. ${ }^{14}$ In this work, the volume ratio $R_{\mathrm{v}}$ was assumed to be equal to 


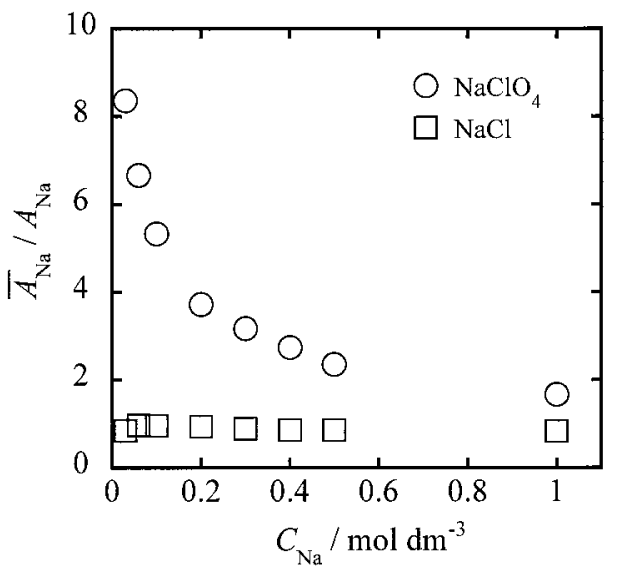

Fig. 3 The ${ }^{23} \mathrm{Na}$ NMR signal intensity ratios of $\mathrm{Na}^{+}$in the amphoteric ion-exchange resin AMP01 to that in the equilibrium solution for the $\mathrm{NaCl}$ and $\mathrm{NaClO}_{4}$ systems.

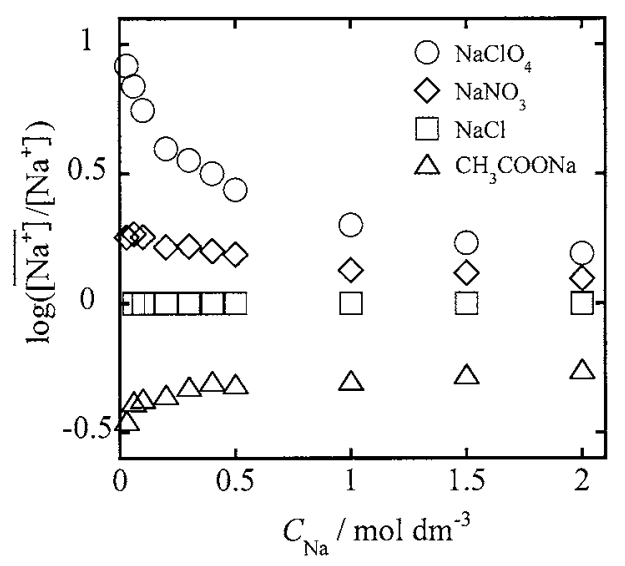

Fig. 4 The concentration dependence of $\log \left(\left[\overline{\mathrm{Na}^{+}}\right] /\left[\mathrm{Na}^{+}\right]\right)$for the amphoteric ion-exchange resin AMP01 in equilibrium with some sodium salt solutions.

$\bar{A}_{\mathrm{Na}} / A_{\mathrm{Na}}$ for the $\mathrm{NaCl}$ system, and $\mathrm{Na}^{+}$concentrations in the resin phase and the values of $\log \left(\left[\overline{\mathrm{Na}^{+}}\right] /\left[\mathrm{Na}^{+}\right]\right)$were then evaluated for various sodium salt systems (Fig. 4). The values of $\log \left(\left[\overline{\mathrm{Na}^{+}}\right] /\left[\mathrm{Na}^{+}\right]\right)$for the $\mathrm{NaClO}_{4}$ system were larger than zero and increased with a decrease in the salt concentration. Because of its high affinity, the perchlorate ion is adsorbed onto the amphoteric ion-exchange resin, so that the resin behaves as a kind of cation-exchanger at the low salt concentrations. As a result, the sodium ion invaded into the resin phase to compensate for the charge of the high affinity perchlorate ion and to fulfill the electroneutrality in the resin phase.

From the values of $\log \left(\left[\overline{\mathrm{Na}^{+}}\right] /\left[\mathrm{Na}^{+}\right]\right)$, the following selectivity order could be obtained for some monovalent anions: $\mathrm{ClO}_{4}^{-}>$ $\mathrm{SCN}^{-}>\mathrm{NO}_{3}^{-}>\mathrm{Br}^{-}>\mathrm{Cl}^{-}>\mathrm{CH}_{3} \mathrm{COO}^{-}>\mathrm{PH}_{2} \mathrm{O}_{2}{ }^{-}$. The nature of these anions should play a crucial role in the selectivity for the amphoteric ion-exchange resin, similar to that for amphoteric micelles. ${ }^{17,18}$ The affinity of an anion to the amphoteric ionexchange resin should be correlated with both the dehydration energy of the anion and the electrostatic interaction between the anion and the functional group. ${ }^{19,20}$

\section{Ion exchange properties of the amphoteric ion-exchange resin}

For an ordinary cation exchange process, such as a cation $\mathrm{M}^{\mathrm{n+}}$ being exchanged with sodium ions, the following reaction
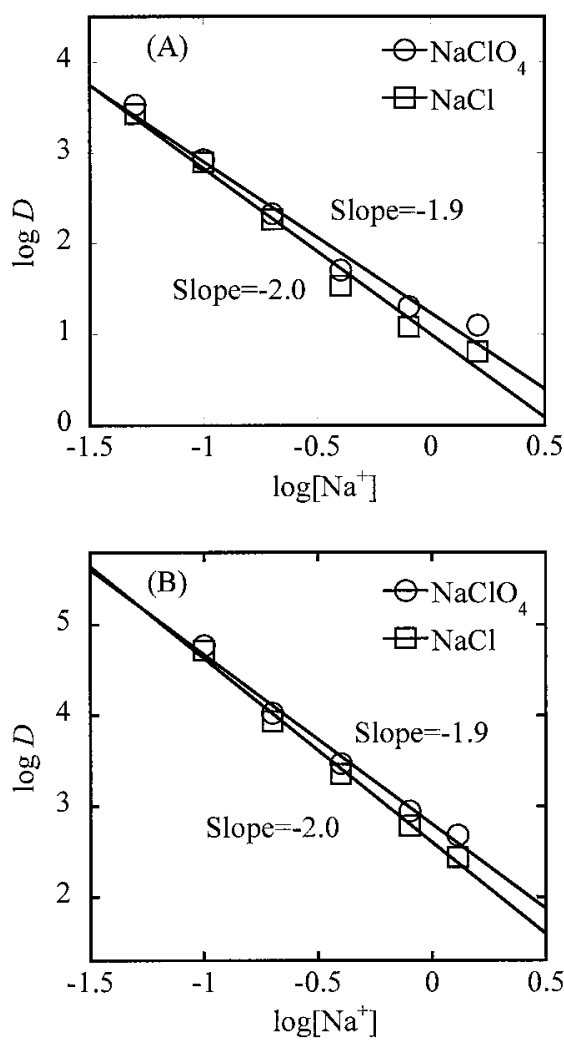

Fig. 5 Distribution coefficients of $\mathrm{Mg}^{2+}$ on the strong and weak acid cation-exchange resins in the $\mathrm{NaCl}$ and $\mathrm{NaClO}_{4}$ solutions. (A) Strong acid cation-exchange resin Bio-Rad 50W-X8, (B) weak acid cation-exchange resin Bio-Rex 70.

takes place:

$$
\mathrm{M}^{\mathrm{n}+}+n \overline{\mathrm{Na}^{+}} \rightleftharpoons \overline{\mathrm{M}^{\mathrm{n}+}}+n \mathrm{Na}^{+}
$$

This process can be characterized by the thermodynamic equilibrium constant, $K$.

$$
\begin{aligned}
& K=\frac{\left[\overline{\mathrm{M}^{\mathrm{n}+}}\right]\left[\mathrm{Na}^{+}\right]^{\mathrm{n}} \bar{\gamma}_{\mathrm{M}} \gamma_{\mathrm{Na}}^{\mathrm{n}}}{\left[\mathrm{M}^{\mathrm{n}+}\right]\left[\mathrm{Na}^{+}\right]^{\mathrm{n}} \gamma_{\mathrm{M}} \bar{\gamma}_{\mathrm{Na}}^{\mathrm{n}}}=D \times \frac{\left[\mathrm{Na}^{+}\right]^{\mathrm{n}}}{\left[\overline{\mathrm{Na}}^{+}\right]^{\mathrm{n}}} \times G \\
& \left(D=\left[\overline{\mathrm{M}^{\mathrm{n}+}}\right] /\left[\mathrm{M}^{\mathrm{n}+}\right], G=\bar{\gamma}_{\mathrm{M}} \gamma_{\mathrm{Na}}^{\mathrm{n}} /\left(\gamma_{\mathrm{M}} \bar{\gamma}_{\mathrm{Na}}^{\mathrm{n}}\right)\right)
\end{aligned}
$$

The ion exchange of $\mathrm{M}^{\mathrm{n}+}$ is controlled by the concentration of the competing sodium ion.

$$
\log D=-n \log \left[\mathrm{Na}^{+}\right]+n \log \left[\overline{\mathrm{Na}^{+}}\right]+\log K-\log G
$$

If $\mathrm{M}^{\mathrm{n}+}$ was present in a trace concentration, the terms of $n \log \left[\overline{\mathrm{Na}^{+}}\right]+\log K-\log G$ could be assumed to be constant for a cation-exchange resin of the $\mathrm{Na}^{+}$form, so that the $\log D$ vs. $\log \left[\mathrm{Na}^{+}\right]$plot should show a linear relationship with a slope of $-n .^{21}$ The plots for the ion exchange of $\mathrm{Mg}^{2+}$ in the $\mathrm{NaCl}$ and $\mathrm{NaClO}_{4}$ solutions showed linear relationships with slopes of $c a$. -2 for both strong and weak acid cation-exchange resins (Fig. 5).

The same experiment has been done for the amphoteric ionexchange resin AMP01 (Fig. 6). Under the experimental conditions, the protonation of the carboxylate in the functional group could be ignored (the protonation will be discussed in the following section). The ion exchange behaviors of the amphoteric ion-exchange resin were quite different from those of the ordinary cation-exchange resins, because the 

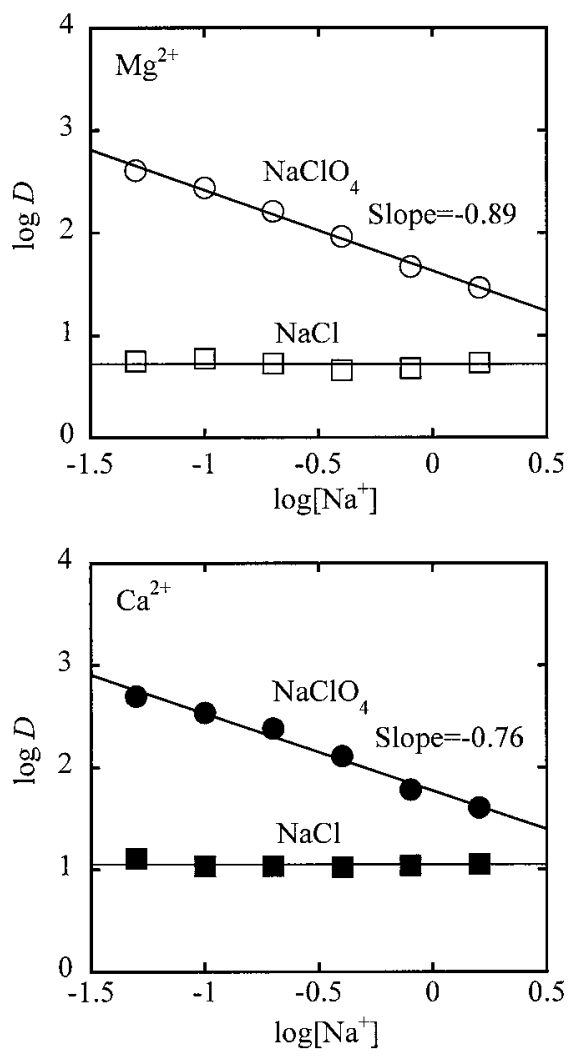

Fig. 6 Distribution coefficients of $\mathrm{Mg}^{2+}$ and $\mathrm{Ca}^{2+}$ on the amphoteric ion-exchange resin $\mathrm{AMP01}$ in the $\mathrm{NaCl}$ or $\mathrm{NaClO}_{4}$ solutions.

concentration of competing sodium ion in the amphoteric ionexchange resin appreciably changed together with the concentration in the external solution. For the $\mathrm{NaCl}$ system, the $\log D$ values of $\mathrm{Mg}^{2+}$ and $\mathrm{Ca}^{2+}$ for AMP01 were almost constant irrespective of the salt concentrations (Fig. 6). This means that the values of $\log \left(\left[\overline{\mathrm{Na}^{+}}\right] /\left[\mathrm{Na}^{+}\right]\right)$were almost constant in this system. Such a phenomenon should occur as a result of the same $\mathrm{Na}^{+}$concentrations between the resin phase and the external solution in equilibrium, as we already mentioned in the previous section. For the $\mathrm{NaClO}_{4}$ system, however, the $\log D$ values were dependent on the salt concentrations, and the $\log D$ vs. $\log \left[\mathrm{Na}^{+}\right]$plots showed linear relationships with slopes not being -2 (Fig. 6). Using the $\log \left(\left[\overline{\mathrm{Na}^{+}}\right] /\left[\mathrm{Na}^{+}\right]\right)$values estimated by the NMR method, we re-plotted the $\log D$ data of $\mathrm{Mg}^{2+}$ and $\mathrm{Ca}^{2+}$ for the $\mathrm{NaClO}_{4}$ system (Fig. 6) versus the $\log \left(\left[\mathrm{Na}^{+}\right] /\left[\overline{\mathrm{Na}^{+}}\right]\right)$ values according to the following equation:

$$
\log D=-2 \log \frac{\left[\mathrm{Na}^{+}\right]}{\left[\mathrm{Na}^{+}\right]}+\log K-\log G
$$

As shown in Fig. 7, fairly good linear relationships with slopes of $c a$. -2 were obtained even in the case of the amphoteric ionexchange resin. The same results were obtained for the ion exchanges on DSR01 in each sodium salt solution.

\section{Protonation of the amphoteric ion-exchange resin}

The same influence of the simple salts should also be observed for the protonation behavior of the amphoteric ion-exchange resin. The protonation equilibrium of the functional group and its protonation constant, $\bar{K}_{\mathrm{H}}$, can be written as:

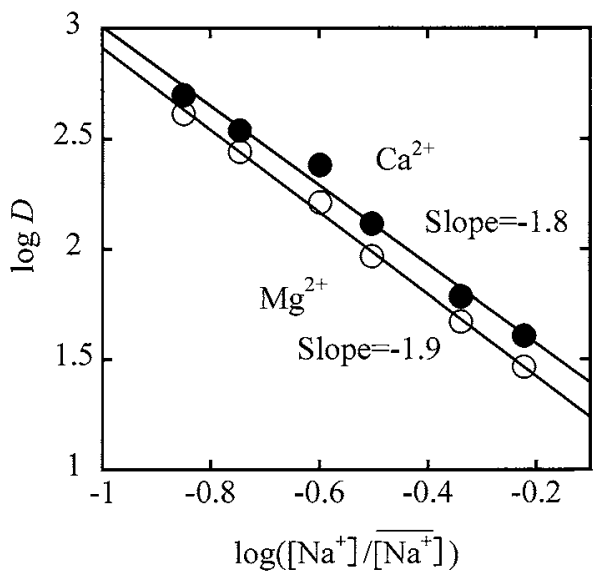

Fig. 7 The $\log D$ vs. $\log \left(\left[\mathrm{Na}^{+}\right] /\left[\overline{\left.\mathrm{Na}^{+}\right]}\right)\right.$plots for the ion exchanges of $\mathrm{Mg}^{2+}$ and $\mathrm{Ca}^{2+}$ on the amphoteric ion-exchange resin AMP01 in the $\mathrm{NaClO}_{4}$ solutions.

$$
\bar{K}_{\mathrm{H}}=\frac{\left[\overline{\mathrm{R}-\mathrm{CH}_{2} \mathrm{~N}^{+}\left(\mathrm{CH}_{3}\right)_{2} \mathrm{CH}_{2} \mathrm{COOH}}\right]}{\left[\overline{\left.\mathrm{R}-\mathrm{CH}_{2} \mathrm{~N}^{+}\left(\mathrm{CH}_{3}\right)_{2} \mathrm{CH}_{2} \mathrm{COO}^{-}\right]\left[\mathrm{H}^{+}\right]}\right.}=\frac{1-\alpha}{\alpha\left[\overline{\mathrm{H}^{+}}\right]} .
$$

Because the hydrogen ion concentration in the resin phase cannot be measured directly, the apparent protontion constant, $K_{\text {app}}$, has been conveniently used.

$$
K_{\text {app }}=\frac{\left[\overline{\mathrm{R}-\mathrm{CH}_{2} \mathrm{~N}^{+}\left(\mathrm{CH}_{3}\right)_{2} \mathrm{CH}_{2} \mathrm{COOH}}\right]}{\left[\overline{\left.\mathrm{R}-\mathrm{CH}_{2} \mathrm{~N}^{+}\left(\mathrm{CH}_{3}\right)_{2} \mathrm{CH}_{2} \mathrm{COO}^{-}\right]\left[\mathrm{H}^{+}\right]}\right.}=\frac{1-\alpha}{\alpha\left[\mathrm{H}^{+}\right]}
$$

The following equation can be obtained from Eqs. (6) and (7) using the Donnan equation, where the quotient of the activity coefficients is assumed to be 1 .

$$
\log \bar{K}_{\mathrm{H}}=\log K_{\text {app }}-\log \frac{\left[\overline{\mathrm{H}^{+}}\right]}{\left[\mathrm{H}^{+}\right]}=\log K_{\text {app }}-\log \frac{\left[\overline{\mathrm{Na}^{+}}\right]}{\left[\mathrm{Na}^{+}\right]}
$$

We evaluated the apparent protonation constants of the functional group from potentiometric data for the $\mathrm{NaCl}$ and $\mathrm{NaClO}_{4}$ systems. Figure 8 shows the $\log K_{\text {app }} v s .1-\alpha$ plots for DSR01. The $\log K_{\text {app }}$ values decreased with an increase in the degree of protonation, $1-\alpha$. Once the functional group is protonated, the positive charge of the quaternary ammonium in the functional group disturbs the subsequent invasion of protons, so that one protonation makes the next protonation difficult. For the $\mathrm{NaCl}$ system, the $\log K_{\text {app }}$ values were greatly dependent on the salt concentrations. Due to the invasion of the salt, the dependence of $\log K_{\text {app }}$ on the protonation degree is less pronounced at the high salt concentrations, especially at values higher than 0.5 for the $\mathrm{NaClO}_{4}$ system. At the zero protonation degree, the $\log K_{\text {app }}$ values were 2.7 for the $\mathrm{NaCl}$ system and 3.3 for the $\mathrm{NaClO}_{4}$ system by the extrapolation of $\log K_{\text {app }}$ to $1-\alpha=0$.

According to the conventional analysis, ${ }^{22-24}$ the Donnan distribution term, $\log \left(\left[\overline{\mathrm{Na}^{+}}\right] /\left[\mathrm{Na}^{+}\right]\right)$, can be assumed to be zero at zero protonation degree, which means that the proton concentrations are the same between the resin phase and the equilibrium solution. If this assumption was valid in the present systems, the logarithm of the intrinsic acid dissociation constant of the functional group, $\log \bar{K}_{\mathrm{H}}$, could be evaluated by the extrapolation of the $\log K_{\text {app }}$ values to the zero protonation degree. As we discussed in the previous sections, the Donnan distribution terms for the $\mathrm{NaCl}$ system should be zero at the zero protonation degree. Therefore, $\log \bar{K}_{\mathrm{H}}$ was determined to be 2.7 

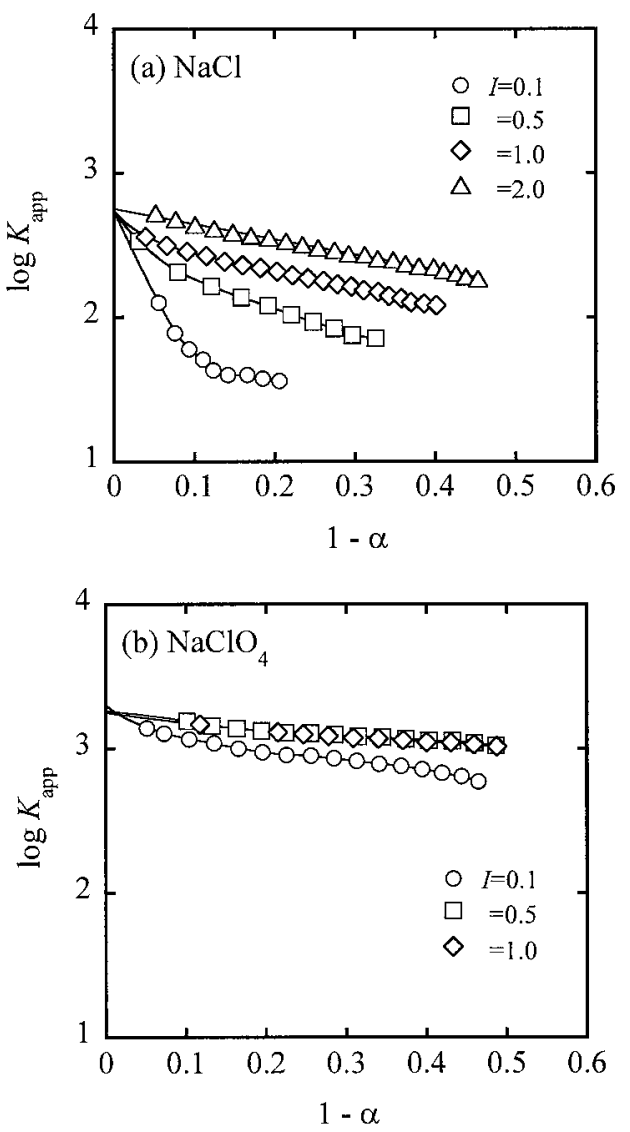

Fig. 8 Apparent protonation constants of the amphoteric ionexchange resin DSR01 in equilibrium with (a) $\mathrm{NaCl}$ or (b) $\mathrm{NaClO}_{4}$ solutions.

by the extrapolation analysis. For the $\mathrm{NaClO}_{4}$ system, on the other hand, the Donnan distribution terms were not zero even at the zero protonation degree. We should evaluate the intrinsic acid dissociation constant of the functional group according to Eq. (8) using the Donnan distribution terms estimated by the ${ }^{23} \mathrm{Na}$ NMR method. The estimated $\log \bar{K}_{\mathrm{H}}$ values for the $\mathrm{NaClO}_{4}$ system were $2.5(I=0.1), 2.8(I=0.5)$ and $2.9(I=1.0)$. Because of the high affinity of the perchlorate ion, the log $K_{\text {app }}$ values for the $\mathrm{NaClO}_{4}$ system were higher than those for the $\mathrm{NaCl}$ system; however, the intrinsic acid dissociation constants were almost the same.

\section{Conclusions}

The concentrations of the competing sodium ion in the amphoteric ion-exchange resin were evaluated for various sodium salt systems by the ${ }^{23} \mathrm{Na}$ NMR method. For the $\mathrm{NaCl}$ system, the concentration of sodium ion in the resin phase was almost the same as that in the equilibrium solution. The values of $\log \left(\left[\overline{\mathrm{Na}^{+}}\right] /\left[\mathrm{Na}^{+}\right]\right)$for the $\mathrm{NaClO}_{4}$ system were larger than zero, and became greater at the low concentrations. On the basis of this information, we clarified the ion exchange behaviors of $\mathrm{Mg}^{2+}$ and $\mathrm{Ca}^{2+}$ on the amphoteric ion-exchange resin in the $\mathrm{NaCl}$ and $\mathrm{NaClO}_{4}$ solutions. Understanding the influence of the simple salts on the ion exchange properties of the amphoteric ion-exchange resin led us also to the correct interpretation of the protonation equilibrium of the carboxylate in the functional group of the resin. Similar phenomena would be observed for amphoteric micelles and membranes, or even for living cells.

\section{Acknowledgements}

We thank Mitsubishi Chemical Corporation and Nippon Rensui Corporation for their kind donation of the DIAION ionexchange resins. We are also grateful for the financial support from the Salt Science Research Foundation (No. 0413).

\section{References}

1. P. N. Nesterenko and P. R. Haddad, Anal. Sci., 2000, 16, 565.

2. M. Goto, N. Hayashi, and S. Goto, Sep. Sci. Technol., 1983, 18,475 .

3. R. Dybczyński and Z. Samczyński, J. Radioanal. Nucl. Chem., 1991, 150, 143.

4. Z. Samczyński and R. Dybczyński, J. Chromatogr., A, 1997, 789, 157.

5. Y. Miyazaki and M. Fujiwara, Bull. Fukuoka Univ. Edu., 2006, 55, 23.

6. G. L. Gaines and H. C. Thomas, J. Phys. Chem., 1953, 21, 714.

7. E. Högfeldt, React. Polym., 1988, 7, 81.

8. A. Marton, Pure Appl. Chem., 1997, 69, 1481.

9. G. Kura, Y. Miyazaki, H. Waki, and A. Marton, React. Funct. Polym., 1998, 38, 197.

10. C. Shao, Y. Miyazaki, S. Matsuoka, K. Yoshimura, and H. Sakashita, Macromolecules, 2000, 33, 19.

11. A. Marton and Y. Miyazaki, Prog. Colloid Polym. Sci., 2001, 117, 153.

12. A. Marton, H. Sakashita, Y. Miura, E. Hiramatsu, and Y. Miyazaki, Talanta, 2003, 59, 217.

13. Y. Miyazaki, S. Matsuoka, Y. Miura, H. Sakashita, and K. Yoshimura, Polyhedron, 2005, 24, 985.

14. Y. Miyazaki, G. Kura, H. Tsuzuki, and H. Sakashita, J. Chem. Soc., Faraday Trans., 1996, 92, 3587.

15. K. Yoshimura, Y. Miyazaki, F. Ota, S. Matsuoka, and H. Sakashita, J. Chem. Soc., Faraday Trans., 1998, 94, 683.

16. G. Gran, Analyst, 1952, 77, 661.

17. T. Masudo and T. Okada, Phys. Chem. Chem. Phys., 1999, 1,3577 .

18. K. Iso and T. Okada, Langmuir, 2000, 16, 9199.

19. T. Okada and M. Harada, Anal. Chem., 2004, 76, 4564.

20. M. Harada and T. Okada, J. Chromatogr., A, 2005, 1085, 3.

21. K. Dorfner (ed.), "ION Exchangers", 1991, Walter de Gruyter, Berlin, New York.

22. T. Miyajima, "Ion Exchange and Solvent Extraction", ed. J. A. Marinsky and Y. Marcus, 1995, Vol. 12, Marcel Dekker Inc., New York, Basel, Hong Kong, 275.

23. R. Biesuz, A. A. Zagorodni, and M. Muhammed, J. Phys. Chem. B, 2001, 105, 4721.

24. C. Rey-Castro, R. Herreo, and M. E. Sastre de Vincente, J. Electroanal. Chem., 2004, 564, 223. 